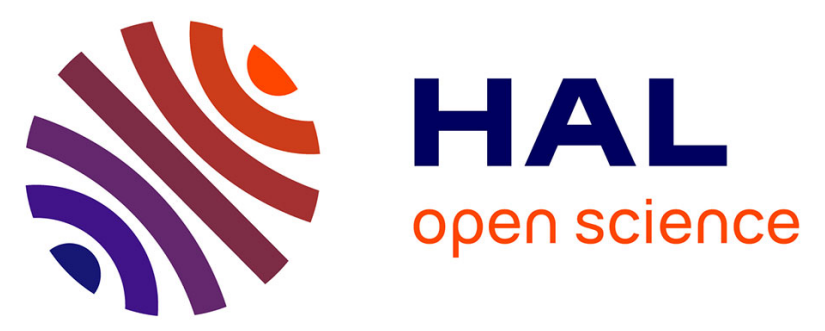

\title{
EXPERIMENTAL STUDY OF THE LASER INDUCED PLASMA IN WELDING CONDITIONS WITH CONTINUOUS HIGH POWER CO2 LASERS
}

A. Poueyo, L. Sabatier, G. Deshors, R. Fabbro, A. de Frutos, D. Bermejo, J. Orza

\section{To cite this version:}

A. Poueyo, L. Sabatier, G. Deshors, R. Fabbro, A. de Frutos, et al.. EXPERIMENTAL STUDY OF THE LASER INDUCED PLASMA IN WELDING CONDITIONS WITH CONTINUOUS HIGH POWER CO2 LASERS. Journal de Physique IV Proceedings, 1991, 01 (C7), pp.C7-183-C7-186. 10.1051/jp4:1991748 . jpa-00250990

HAL Id: jpa-00250990 https://hal.science/jpa-00250990

Submitted on 1 Jan 1991

HAL is a multi-disciplinary open access archive for the deposit and dissemination of scientific research documents, whether they are published or not. The documents may come from teaching and research institutions in France or abroad, or from public or private research centers.
L'archive ouverte pluridisciplinaire HAL, est destinée au dépôt et à la diffusion de documents scientifiques de niveau recherche, publiés ou non, émanant des établissements d'enseignement et de recherche français ou étrangers, des laboratoires publics ou privés. 


\title{
EXPERIMENTAL STUDY OF THE LASER INDUCED PLASMA IN WELDING CONDITIONS WITH CONTINUOUS HIGH POWER $\mathrm{CO}_{2}$ LASERS
}

\author{
A. POUEYO, L. SABATIER, G. DESHORS, R. FABBRO, A.M. de FRUTOS*, D. BERMEJO** and \\ J.M. ORZA** \\ Laboratoire d'Applications des Lasers de Puissance (Unité mixte E.T.C.A./C.N.R.S.), \\ 16 bis avenue Prieur de la Côte d'Or, F-94114 Arcueil cedex, France \\ *Universidad de Valladolid, Dpto. de Fisica Aplicada III, Spain \\ **Instituto de la Estructura de la Materia, C.S.I.C. Madrid, Spain
}

\begin{abstract}
It is well known that the metallic plasmas observed in laser welding play an important role in energy transfert during laser materials processing. They are critical to understanding energy transport to the workpiece. This paper reports an experimental investigation characterizing the plasma using visible emission -spectroscopy. These experiments provided the electron density and temperature distributions $\left(-10^{17} \mathrm{~cm}^{-3}\right.$ and $\left.6000-7000{ }^{\circ} \mathrm{K}\right)$. The experimental data are then used to determine laser attenuation and refraction as the beam propagate through the plasma column. These results are compared with direct absorption measurements where an integrating spere has been used, and with a numerical simulation. It was observed that the absorption coefficient is closely correlated to the spatial and temporal behaviour of the plasma and the effect of refraction is of primary importance for laser processing when using other gases than helium at high laser intensity.
\end{abstract}

\section{INTRODUCTION}

A wider use of laser welding in an industrial point of vue requires an understanding of the interaction between laser and matter which ought to absorb an ever increasing proportion of energy.

For low laser intensities, it is commonly known that laser coupling is increased whenever a plasma is present in the interaction area. On the other hand, for high laser intensities, the plasma may shield the workpiece if no appropriate assisting gas such as helium is used. In order to understand and improve the procedure, we determined the microscopic parameters of a plasma created by two different lasers whose output power ranged from 1 to $15 \mathrm{~kW}$ and whose beam was focalized onto pure iron targets. The first one delivered an output intensity of about $1 \mathrm{MW} / \mathrm{cm}^{2}$ and the other one delivered an intensity close to $5 \mathrm{MW} / \mathrm{cm}^{2}$. Spectroscopic studies of plasma emission in the visible wavelength range were carried out for the derivation of both electronic temperature and density, and of the scale length as well. The knowledge of these parameters allowed us to get an estimation of the mechanisms of coupling. Using a simple technique where the reflected light is collected by an integrating sphere, we measured this coupling precisely and got its temporal resolution in the same time.

Moreover, we considered the refraction of the laser due to the plasma column. We can notice that the nature of the shielding gas is of a great importance at high intensities: indeed, the laser-supported-combustion waves are completely different and the refraction effect is enhenced using argon for exemple.

\section{EXPERIMENTAL SET-UP AND PROCEDURES}

A general view of the experimental set-up for the measurement of the total reflectivity during the interaction and for the spectroscopic measurements is presented in ref 1 . The visible-range photodiode followed the space-integrated emission of the plasma plume, and a length of only 1 to $2 \mathrm{~mm}$ above the target surface was monitored.

In order to determine the plasma parameters, we used the spectroscopic arrangement described in reference 2. Concerning the derivation of the temperature, we used the $442.73 \mathrm{~nm}$ and $442.25 \mathrm{~nm}$ lines from the $\mathrm{Fe}(\mathrm{I})$ plasma spectrum From both absolute emissivities of the lines of interest, we could get a straightforward determination of the plasma temperature. The derivation of the electronic density was based on the Stark broadening effect. We chose the $538.337 \mathrm{~nm}$ line, just as in ref.3, because in litterature4-5-6, its Stark coefficient was given with a much better accuracy4 than for any other one. Furthermore, this line under study turned out to be relatively isolated in the spectrum ${ }^{7}$. Moreover, before anything, some experimental conditions were check out: thermodynamic equilibrium, selfabsorption for the line of interest, and measurement of the instrumental fonction ${ }^{3}$.

For the absorption measurements, we used an integrating sphere. The diagnostic was based on the signal recorded by the visible range photodiode which visualised the plasma emission, and by the signal of the $\mathrm{CO} 2$ reflected radiation. This 
solution allows to follow the coupling with a characteristic time limited by the transit time of the photons within the sphere, which is typically of the order of a few nanoseconds. These experiments were carried out with different laser intensities and the nature of the shielding gas was changed as well.

\section{EXPERIMENTAL RESULTS}

\subsection{Spectroscopic results.}

The experiments were performed in pulsed conditions for the sake of simplicity: a 200 ms pulse was released when the $25 \mathrm{~kW}$ laser was used and a $10 \mathrm{~ms}$ one with the $1 \mathrm{~kW}$ laser. However, some experiments were carried out with a target moving at $20 \mathrm{~mm} / \mathrm{s}$, this situation corresponding quite satisfactorily with a realistic treatement. The results agree with each other: this confirms the validity of the static plasma study. The spatial variation of the plasma parameters along the laser axis are displayed in figures 1 and 2.

We did not perform Abel's deconvolution on these experimental results, but numerical simulations were conducted in the aim of getting a more precise estimation of the effect of integration along the diameter of the plasma column.

Several realistic $\mathrm{Ne}$ and $\mathrm{Te}$ radial profiles were tested. A numerical integration of the emissivity of the line under study along the observation axis gives a mean half width of the theorical Ne profile and the corresponding electronic density derivated this way can be compared with the theorical density on the axis. For the different tested electronic density profiles, it appeared that this overall axial density is about half of the maximum density along the profile. In a similary way but considering the intensity ratio of the lines of interst, the electronic temperatures integrated and theorical were found to be quite close.

All the experiments at $5 \mathrm{MW} / \mathrm{cm}^{2}$ used helium as shielding gas at a blowing rate of $5 \mathrm{l} / \mathrm{min}$. On the other hand, at lower intensities, different gases were considered. Obviously, under such experimental conditions, the nature of this shielding gas does not have a significant influence on both temperature and density. Besides, it was impossible to use another gas than helium at high power intensities. A shielding plasma which became detached from the workpiece could be observed and the visible photodiode which was visualizing a volume of about $1 \mathrm{~mm}^{3}$ on the target surface recorded an intensity peak only in the beginning and at the end of the laser impulsion, whenever argon or nitrogen was used.

These results led to an estimate of the absorption within the plasma column. The Inverse Bremsstrahlung absorption coefficient is given by the following equation:

$$
\mathrm{K}\left(\mathrm{cm}^{-1}\right)=3.10^{-35} \frac{\mathrm{Ne}^{2}\left(\mathrm{~cm}^{-3}\right)}{\mathrm{Te}^{3 / 2}(\mathrm{eV})}
$$

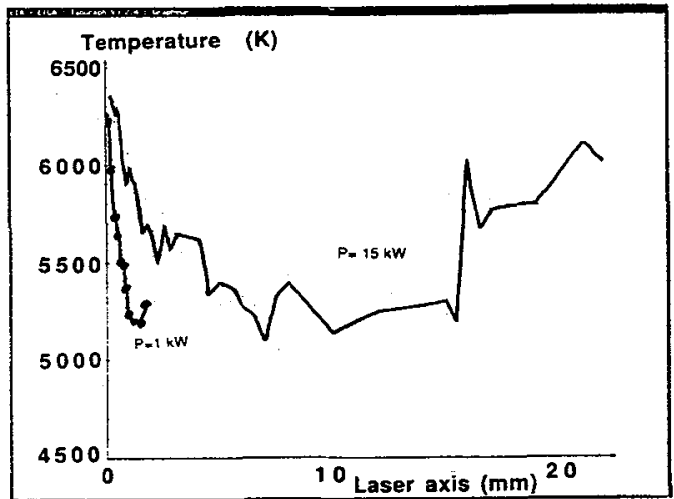

Fig 1: Temperature profil along the laser beam axis at 1 and $5 \mathrm{MW} / \mathrm{cm}^{2}$

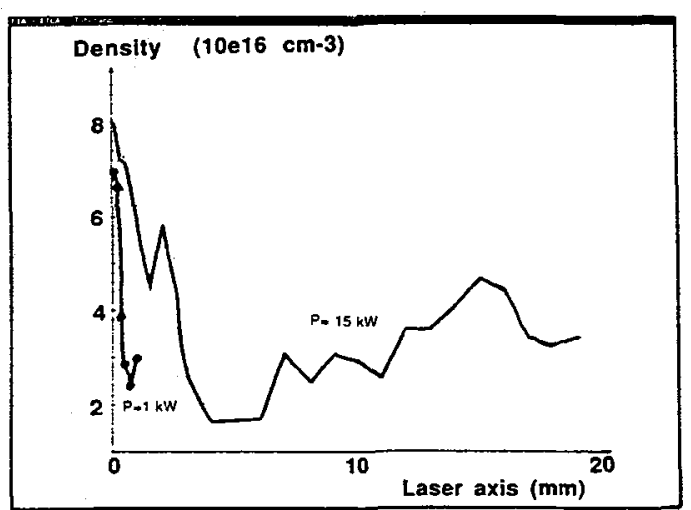

Fig 2: Electronic density profil along the laser beam axis at 1 and $5 \mathrm{MW} / \mathrm{cm}^{2}$

Using the results from figures 1 and 2 , the integral of $\mathrm{K}$ along the incoming light path leads to a $50 \%$ transmission for a $15 \mathrm{~kW}$ incident power and $92 \%$ in the case of $1 \mathrm{~kW}$. This indicates that the plasma is rather transparent for the laser beam, whenever helium is used as shielding gas. Direct reflectivity measurements agree with this, as we shall see it in the following paragraph. 


\subsection{Reflectivity results.}

With the help of the set-up we used in this experiment, correlations between photodiode and reflectivity recordings, with a $1 \mathrm{~kW}$ focalized energy, could be detected. Figure 3 displays these correiations: any local maximum in the photodiode recording corresponds to a local minimum in reflectivity. From this observation, by measuring the reflectivity without plasma (Rv) and in the presence of plasma (Rp), when no key-hole is present, we can evaluate the plasma transmission ${ }^{1}$. which is given by: $T=\left(\frac{R_{p}}{R_{v}}\right)^{1 / 2}$. We obtained a transmission coefficient of about $75 \%$ in our experimental conditions (fig. 3 )

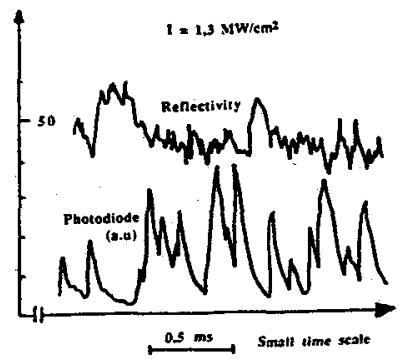

Fig 3: Time dependance of target reflectivity and of the visible luminosity of the plasma Incident laser intensities : $1,310^{6} \mathrm{~W} / \mathrm{cm}^{2}$

\section{DISCUSSION}

Another crucial point of interest in this study is the estimate of the effects of refraction by the plasma column.

The knowledge of the electronic density allows us to estimate the refraction index gradient. From this result, we can then have an idea of the imporance of the defocalisation of the laser beam at the target surface. The refractive index gradient is approximated by: $\nabla \mathrm{n}=\frac{1}{2 \mathrm{Nc}} \nabla \mathrm{Ne}$. where $\mathrm{Nc}$ is the critical density, which is equal to $10^{19} \mathrm{~cm}^{-3}$ for the $\mathrm{CO}_{2}$ laser wavelength.

The deflection angle of the laser beam propagating along the plasma column is then given by:

$\theta=\frac{\nabla n}{n} L=\frac{L}{2 N c} \nabla n=\frac{N e}{2 N c} \frac{L}{R}$ where $L$ is the length of propagation corresponding to the length of the plasma and $R$ is the caracteristic gradient length of the refraction index which typically is the radius of the plasma column.

In a first step, we shall consider the case of helium as shielding gas, which leads to a plasma localized upon the target. Using typical values of these parameters $\left(L \approx 20 \mathrm{~mm}, R=5 \mathrm{~mm}\right.$, Ne=5 $\left.10^{16} \mathrm{~cm}^{3}\right)$, we obtained $\theta \approx 0.01$ rad. The initial focal radius was about $250 \mu \mathrm{m}$, and therefore, a $80 \%$ increase in the focal radius was expected due to the refraction effect. This corresponds to a $70 \%$ decrease in the mean intensity on the target surface.

In a second step, it is quite interesting to consider the reflectivity results during the welding process with argon and nitrogen as shielding gases (the incident intensity being set up at $5 \mathrm{MW} / \mathrm{cm}^{2}$ ).

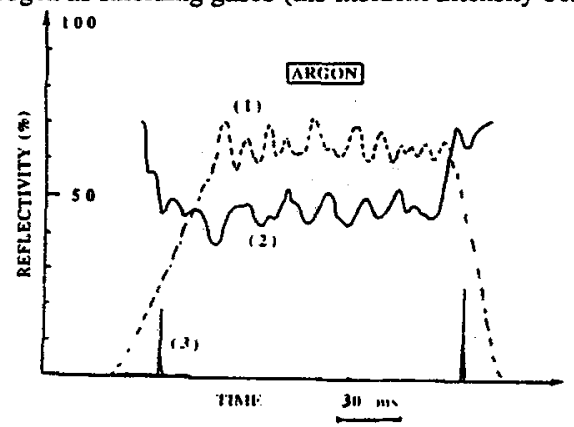

Fig. 4 : Effect of the shielding gases. Curve (1) coresponds to a $200 \mathrm{~ms}$ laser pulse (a.u). The intensity on the target surface is about $5 \mathrm{MW} / \mathrm{cm}^{2}$. Curve (2) is a target reflectivity record. Curve (3) is a photodiode signal (a.u). It can be seen that the plasma is only present on the target surface in the begening and at the end of the laser pulse.

In these conditions, the absorption measurements (fig.4) show that only $50 \%$ of the incident laser light is absorbed. Moreover, the corresponding photodiode signal (fig.4) shows that the plasma is no longer existing at the workpiece surface. In fact, the plasma is localized at several centimeters above the target surface. Furthermore, in these conditions, we observed that the surface was slightly altered by the laser radiation, with no keyhole formation. As only half of the incoming laser energy is absorbed by the intense plasma which gets detached from the surface, this means that an important fraction of the laser beam is refracted while propagating across the plasma, and is consequently strongly. defocused at the target surface. Eventually, these results indicate that this detached plasma mainly induces a strong effect of defocusing of the laser light at the target surface, and not a strong shielding effect as it is usually admitted.

Some numerical simulations were carried out to show the influence of the plasma on the laser propagation. The laser beam is divided into 100 beams which propagate through the plasma plume. The other parameters are the focal length, the focalisation, the plasma density profile, the plasma location. The absorption of the incoming light was not considered in the calculation of the intensity disuribution on the target surface. The results obtained are presented in figure 5. It becomes obvious that the plasma strongly modifies the laser intensity distribution while propagating along the plasma column. 


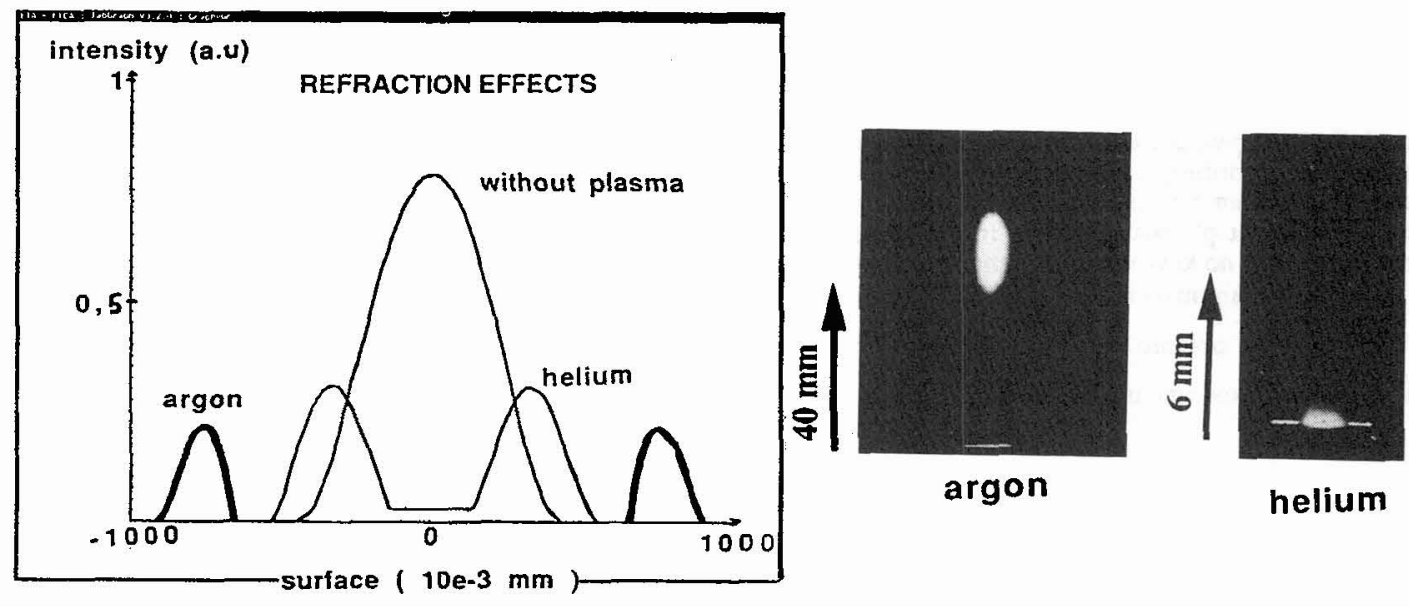

Fig 5: Effects of refraction: intensity distribution on the surface target. For a similar electronic density profil, the decrease of the intensity on the target in the focal volume is enhanced when Argon is used as shielding gas. The photograph show the two different plasmas obtained using Helium or Argon.

\section{CONCLUSION}

A spectroscopic study has been carried out in the aim of derivating the plasma parameters in laser welding conditions. From these results, the transmission of the plasma column was calculated. Direct reflectivity measurements were also performed. When helium was used as shielding gas, it appeared that the plasma does not play a significant role in the absorption of the laser radiation, even at high intensities, as it is usually thought. Nevertheless, the effects of refraction seem to play an important role in all cases and can probably explain the high level of the observed piasma fluctuations.

\section{REFERENCES}

1. R. Fabbro, D. Bermejo, J.M. Orza, L. Sabatier, L. Leprince and V. Granier "Absorption measurements in continuous high-power CO2 laser processing of materials". Proceedings of SPIE, Vol.1276, p.461(1990)

2. D. Bermejo, R. Fabbro, L. Sabatier, L. Leprince and J.M. Orza." Spectroscopic studies of iron plasmas induced by continuous high power $\mathrm{CO}_{2}$ laser ${ }^{n}$ Proceedings of SPIE, Vol. 1279, p.118

3. A.M. de Frutos, L. Sabatier, A. Poueyo, R. Fabbro, D. Bermejo and J.M. Orza." Spectroscopic determination of the parameters of an iron plasma produced by a $\mathrm{CO}_{2}$ laser" G.C.L. Madrid 1990, to be published.

4. N Konjevic, M.S. Dimitrijevic and W.L. Wiese. J. Phys. Chem. Ref. Data 13 (1984)

5. J. Moity, P.E. Pieri and J. Richou, Astron. Astrophys. 45,417 (1975)

6. S. Freudenstein and J: Cooper, Astron. Astrophys. 71 , 283 (1979)

7. A. Poueyo, L. Sabatier, G. Deshors, R. Fabbro, A.M. de Frutos, "Experimental study of the laser induced plasma in welding conditions with continuous high power $\mathrm{CO}_{2}$ lasers." to be published in the Proceedings of SPIE (The Hague, 11-15 March 1991) 